\title{
A framework for supporting planning and development of infrastructure projects from a societal perspective
}

\author{
H. Doloi ${ }^{a}$ \\ ${ }^{a}$ Faculty of Architecture, Building and Planning, The University of Melbourne, Australia \\ E-mail: hdoloi@unimelb.edu.au
}

\begin{abstract}
Capital projects are the backbones of our society and they must go through an evolutionary process of repeated planning and analysis cycles. Ensuring a building is structurally sound, or that a tallest building will add a new image to a city is not enough: new infrastructure and urban development must be rationalised in their planning, design and operations ensuring fitness-for-purpose and adequate societal value contributions (e.g. local resource utilisation, community wealth creation etc.) within the community. In order to ensure value creation and complete social acceptance, projects must be planned and developed by aligning the needs and requirements of the wider community proactively. This research develops an experimental framework aiming to facilitate holistic decision making on capital projects. Adopting the Social Network Analysis (SNA) based innovative methodology, a framework for quantifying social value in infrastructure projects has been demonstrated. Based on an Australia case study, the process of integration of representative community views of extended stakeholders over planning, development and operation phases in capital projects has been highlighted. Social Network Analysis (SNA) is considered to be one of the highly appropriate research methods for enquiring the complex patterns of interactions between stakeholders associated with the capital projects. The new framework will potentially assist in replacing the traditional top-down planning processes and promoting sophistication in developing socially responsive infrastructure within built environment.
\end{abstract}

Keywords: Built Infrastructure and Human Factors, project planning, social value, infrastructure

\section{Introduction}

In the next one hundred years, cities will rapidly grow in size and complexity with soaring population growth. Melbourne population is predicted to reach 7 million in 2050 contributing to a total of 35.9 million nationally. Now, more than ever, there is a need to assess the long term needs, performance and social acceptance of infrastructures before they are built. One major weakness in the traditional approach is the poor inclusion of the stakeholders' concerns at the early stage of project planning process (Clarkson 1995).

In order to ensure value creation and complete social acceptance, projects must be planned and developed by aligning the needs and requirements of the wider community proactively (Carrington 2005; Galaskiewcz 1979). One major weakness in the traditional approach is the poor inclusion of the stakeholders' concerns at the early stage of project planning process. Stakeholders are the individual or groups of people who have an interest in the project or are being affected directly or indirectly by the project outcomes, irrespective of their direct contractual relationships with the project sponsors (Doloi et al. 2011, Doloi 2012). While the community consultation processes are used for development of public projects in Australia, the decision making process usually does not reflect any clear integration of the feedback received and the project-specific knowledge gained is often wasted. Current practice seriously lacks any model for allowing consolidation of the consultation feedback in objective decision making process (Elkington 1998, Littig and Griessler 2005). The absence of such capability clearly hinders the use of knowledge gained in community consultation from one project to the planning of the next project. Instead, the stakeholders are often considered as nuisance and their interests treated as constraints in achieving the project objectives. Consequently, projects have suffered serious set-backs due to political, social, environmental and community challenges and fail through statutory processes. (Doloi 2010a, 2010b, 2008)

\section{Objectives of the Research}

The aim of this research is to develop an experimental smart framework that will facilitate holistic decision making from a stakeholder perspective on capital projects. The objectives to be achieved are:

To conduct fundamental research for constructing Social Network Models that integrates representatives of the entire stakeholder community, such as businesses, end-users and neighbourhood communities, for assessment of their interactions and relative stakes over planning, development and operation phases (e.g. life cycle) of capital projects (Doloi 2012, Doloi2011, Doloi and Almahmoud 2012, Prell et al. 2009, Pryke 2012);

- Develop a hierarchical decision model that places benefits to stakeholders and community interests at the core of decision making, in addition to the usual resource and financial considerations (Doloi 
2007,Grimble and Wellard 1997, Maignan and Ferrell 2004);

- To develop fuzzy preference models and intelligent agents for facilitating learning the functional relationships between different level of variables in the decision model, monitoring project information and associating patterns of data with opportunities/risks, determining optimality and forecasting outcomes of proposed decisions based on trends in the project data (Kumar and Ghoshal 1998, Kuo and Xue 1999, Khosla and Dillon 1997, Nwana and Azarmi 1997, Festinger 1949, Gunaratnam and Gero 1994, Fodor and Roubens 1994); and

- $\quad$ To prototype a Smart Information Model (SIM) for demonstrating the effectiveness of holistic decision making using case studies and capacity building in the industry practice (Ballestero and Romero 1998, Blaco et al. 1995, Bortolan 1998, Boussabaine 1996, Bonabeau 2002, Bavelas 1948).

To address these issues, a number of existing research will be integrated into the information model with added capability for benchmarking of social performance and life cycle management of built environment projects.

\section{Background Review}

Project failures are not just related to experiencing delays or cost overruns as typically portrayed in the project management literature or the media. More significantly, failures tend to affect the relevant commercial and operational fundamentals, project fitness for purpose, adaptability, acceptance by the community and users groups and other vital characteristics. Numerous experiences of expensive but failed projects (e.g. School projects from Government's Building Education Revolution (BER) program, Ararat Prison project, East Link project in Melbourne, Southern Cross Railway Station in Melbourne, Docklands Development, Cross City Tunnel in Sydney etc.) show the complete lack of any mechanism to incorporate these factors for ensuring the target outcomes. While development of all these projects may have been rationalised based on at least the traditional cost-benefit analysis, none of these projects have evidently resulted meeting the perceptions of the community at large and hence perceived to have failed to create appropriate value in a societal context. In contrast, however, a project such as the Sydney Opera House with significant problems in design and development did not end up being a failed project in a societal context. Instead, this iconic project added enormous value in Australian social fabric. This is clearly a good example of how perceptions of the end users (internationally in the case of the Sydney Opera House) contribute to the long term social value creation over project lifecycle.
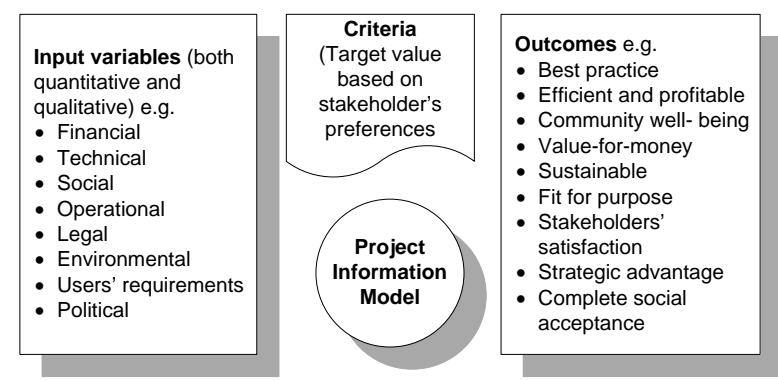

Figure 1: Broad view of input and output variables in project development

Figure 1 shows a broad view of an ideal input-output based Information Model associated with project planning and development. As the input variables are both quantitative and qualitative, these are prone to change with time. Thus the criteria for decision optimisation must not only consist of hard functions based on well-established theories, but also evolutionary soft functions based on community preferences. The processing and learning the entire information in real time should be the key components in the model.

\section{Model Development}

In order to develop the model for analysing stakeholder's needs and requirements and thereby performing relevant analysis on the available feasible solutions, an information model hierarchy of underlying variables needs to be developed. For real time execution of the model on a particular case project, the following steps need to be performed:

1. Determination of the criteria (target values set) for assessment of the project, i.e. financial targets (based on investment policy and market conditions), overall stakeholders satisfaction target and overall social value performance target (both have to be derived for each project) that must be achieved (Table 1 and Figure 2).

2. Estimation of the expected financial outlay based on market conditions, expected satisfaction levels based on stakeholders' network, their position within the network, relative stakes and potential influence and expected total social value performance on each feasible solution is developed (current research capability already permits conduct of this part);

3. Development of ANN models using the indicators in step 2 and train the network using similar data from case study projects (empirical data collected from case studies);

4. Derivation of the expected overall financial status, overall stakeholders' satisfaction level and the overall social value performance points respectively for each of the feasible solutions, using the results from Step 3 and preference rules (Figure 2);

5. Constructing a Decision Table with the results from all the aforementioned analyses (including financial estimates) as per Table 1 format;

6. Locating all solutions that meet the target criteria; and 
7. Locating the most favourable single/hybrid solution by applying Fuzzy preference models (multi-criteria decision modelling).

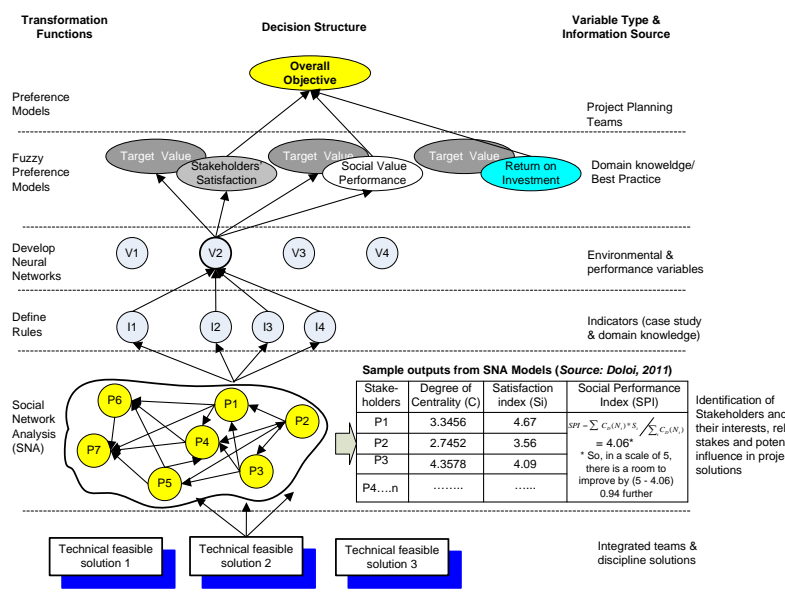

Figure 2: Project Decision Model Hierarchy and Information Sources

The multi-criteria decision modeller will be developed based on variables derived in Social Network Models on case studies and augmented by a Project Reference Group (PRG). The PRG is formed by inviting the representatives of the various stakeholders directly or indirectly involved in the project. Fuzzy preference modelling techniques would be used to determine the relative weighting for these variables. Neural networks, of the Multi-layer Perceptron (MLP) type, would be used for learning the required set of relationships between the high level variables and the associated indicators, and for monitoring and predicting the values of these variables (Lorterapong and Moselhi 1996) .

\section{Application of Social Network Analysis (SNA)}

SNA is a powerful method for collective representation of group of actors (such as individuals or organisations) and their dyadic ties between these actors. The social network perspective provides a clear way of assessing interactions of social entities in order for representing global patterns, locate influential actors relative to others and examine the overall network dynamics. The social network is a multidisciplinary science emerged from social psychology, sociology, statistics, and graph theory where human interactions impacting the outcome of a phenomena is quite pivotal. The first true social network concept in the field of sociology was formulated by Moreno in 1953 for conceptualising the structures of small groups of people produced through friendship patterns and information interactions (Moreno 1953). Extending the concept, Bavelas (1948) and Festinger (1949) laid a solid foundation of 'group dynamics' which later form the backbone of the American Social Psychology in 1960s. While the development of the concept was rapidly spreading out across numerous fields of scientific studies, the most powerful anthropological developments were associated with the work on African societies carried out at the University of Manchester which was codified as one of the first books on Social Networks in Urban Situation (Mitchell 1969).

In recent years, Social Network Analysis (SNA) is becoming increasingly popular as a general methodology for understanding complex patterns of interaction (Carrington, 2005). The network perspective examines actors that are connected directly or indirectly by one or more different relationships. Any theoretically meaningful unit of analysis may be treated as actors such as individuals, groups, organizations, communities, states, or countries. Regardless of unit level, social network analysis describes structure and patterns of relationships, and seeks to understand both their causes and consequences (Haythornthwaite, 1996).

\section{Integration of Stakeholders in the Model}

In complex projects with many stakeholders, application of Social Network Analysis (SNA) provides a platform for integrating their perceptions holistically in the project development process. Conceptually, there are three key elements required to understand for social network analysis. In the network, the 'Nodes' or 'Actors' are entities, persons, organisations, or events. The 'Links' between the nodes represent the relationships of any kind such as transfer of money, communications, friendships, exchange of resources or information etc. (Galaskiewcz, 1979). One of the key characteristics of the network is 'centrality'. Networks may have one or several or even no central actor(s) with links from many actors directed to it, which represents high or low network centrality. A central position within the network indicates the amount of power obtained through the structure and capacity to access information and the other members (Wasserman and Faust, 1994). Thus, SNA is concerned with the structural positions (such as central, isolate, bridging etc.) of actors. If an actor has many links to others in the system, then it has different network characteristics than an actor with fewer links within the system.

In order to assess the social performance in projects, the underlying social needs and necessities within the broader communities involved (directly or indirectly) over the project lifecycle must be accurately understood. For instance, the idea of what really constitutes a decent life for a particular community in relation to a project is highly subjective and it depends on the perceptions of that community. Thus, if personal needs of a community, such as food, housing, health care, freedom and liberty etc. are combined with institutional needs such as education, recreation/leisure, social relationships etc. a much broader of action and opportunity is required in the social value creation process. The major driving force behind society and socialisation in broadest sense is the creation of opportunities to meeting one's need and for that purpose, Malinowski (1988) suggests that categorisation of societal needs across meaningful 
functional systems is essential for shaping and controlling the relationships within the societal structure (Malinowski, 1988).

\section{Analysis and Results}

Making holistic decisions requires balancing the financial gains flowing to promoters and investors on the one hand and the benefits accruable to the community, environment and stakeholders on the other. Table 1 shows how a holistic analysis may be structured and used.

Considering a case project such as construction of a new technology park or a new highway, the solutions in Table 1 are all assumed feasible (generated by the project planners), each has an estimated incremental cost and a corresponding overall stakeholders' satisfaction level and the total social value performance. Both 3 and 4 solutions satisfy all the expected target values set as criteria, though Solution 4 has a higher incremental cost (6.75\%) while 3 has a higher return on investment (27\%). Solution 1 is rejected as it does not meet any of the criteria, while Solution 2 is financially superior but will not meet the target set for the total social value performance. Selection is therefore confined to either 3 or 4 . The question is whether or not the additional investment of 1.20 percentage points $(6.75-5.55)$ of total life cycle cost is worth it, or whether or not the drop in the IRR value by 2 percentage points in Solution 4 relative to Solution 3 is acceptable, given that the latter has an increased satisfaction level by 0.5 and additional total social performance (accruable to the stakeholders and the community) of 5 percentage points of the project base value. Currently, this type of decision is normally made by the sponsors considering mainly the financial merits of each case. However, integrating the input from the extended stakeholders and community alike, the proposed model will facilitate such trade-offs to locate the optimal solution among those which meet the target criteria.

Table 1: Holistic analysis of alternative plans for a given project

\begin{tabular}{|l|l|c|c|c|c|c|c}
\hline $\begin{array}{l}\text { Solution } \\
\text { (plan) } \\
\text { number }\end{array}$ & $\begin{array}{l}\text { Incremental } \\
\text { cost* }\end{array}$ & \multicolumn{2}{|l|}{$\begin{array}{l}\text { Return on investment } \\
\text { (IRR value, in \% } \\
\text { pa)*** }\end{array}$} & \multicolumn{2}{l}{$\begin{array}{l}\text { Overall Stakeholders' } \\
\text { satisfaction level } \\
\text { (index)**** }\end{array}$} & \multicolumn{2}{l}{$\begin{array}{l}\text { Total Social Value } \\
\text { Performance (SVP) } \\
\text { (\% points)**** }\end{array}$} \\
\cline { 3 - 8 } & & Target & Expected & Target & Expected & Target & Expected \\
\hline 1 & 0.75 & 25 & 20 & 4.0 & 3.4 & 20 & 11 \\
\hline 2 & 3.92 & 25 & 31 & 4.0 & 4.1 & 20 & 17 \\
\hline 3 & 5.55 & 25 & 27 & 4.0 & 5.0 & 20 & 21 \\
\hline 4 & 6.75 & 25 & 25 & 4.0 & 5.5 & 20 & 25 \\
\hline
\end{tabular}

As seen in Table 1, the incremental cost is the additional cost in each solution (\% of total project life cycle cost). Financial measure includes key indicators such as IRR, NPV, Cost-Benefit Analysis, Life Cycle Costing etc. Stakeholders' Satisfaction level usually is an index from a scale of 0 for no satisfaction to 6 for best practice solution in the management of non-quantitative variables, derived through the application of Social Network Analysis and the Preference Rules to the indices for all individual variables. The Total Social Value Performance (SVP) is expressed as \% of the overall (consolidated) value contributed by the project in societal context. SVP for individual social issues can be computed at a lower level in the system (Hossain and Silva 2009, Hossain 2009).

Given the dynamic project environment, the input variables will certainly change over time and thus repeated cycles of analysis and replanning will be required. So the real benefit is the feedback that the model (SIM) will provide, and the clarity of how solutions meet the relevant targets and whether or not a hybrid solution that embodies elements of all the aforementioned solutions can be synthesised with superior performance all around. Whole of life financial modelling and part of stakeholders' satisfaction modelling have already been successfully researched and developed by me at the University of Melbourne. Derivation of the overall social value performance as well as research and development of the proposed smart model with required intelligent functions with predictive power remain the challenge being addressed in my fellowship project.

\section{Future Direction}

The research is currently at a very early stage. However, given the uniqueness of the research methods and adopted approach with a clear focus of the stakeholder's needs and requirements in decision making context, the output promises to contribute towards a sophisticated and efficient framework replacing the traditional practices. Thus, the novelty of the research is clearly evident across the concepts, aims, objectives, activities and methodologies. For the very first time, SNA will be used for objective assessment the stakeholders' influence in the project decision process. Thus the innovation in this project is realised in number of fronts. Firstly, the adaptation of Stakeholder Theory for identifying the variables, indicators and criteria associated with project development and operational environment. Secondly, the integration of collection of powerful research methods namely fuzzy preference modelling, artificial neural network and intelligent agents, multi-criteria decision modelling for smart use of information and thereby developing strong predictive models for supporting optimal decision making in development of capital projects. For the first time, the resulting Smart Information Model (SIM) will provide a unique capability for empowering the project owners, policy makers, sponsors alike to developing socially responsive projects.

\section{Conclusions}

The research is aiming to tackle a very important issue of ensuring optimal value creation of capital intensive infrastructure projects in societal context. The unique mechanism of integrating stakeholders' perceptions over project life cycle for optimal planning and development decisions in capital projects is considered to be at the 
forefront in construction research. Quantification of stakeholders' influence with respect to their relative stakes in projects and responsive planning for complete social acceptance will establish a new benchmark on success and failure of capital projects both nationally and internationally. Application of the resulting Smart Information Models in planning, development and operations of capital projects will advance the knowledge base across numerous dimensions including construction, architecture, urban planning and urban renewal and regeneration.

The SNA based approach developed in this research will help the policy makers and industry practitioners better understand the current status of development planning in relation to its capital budgeting and investments programs. The application of research in real life projects will provide convincing evidence to the policy makers and government bureaucrats on the shortfalls of current project development practices and thereby adaptation to the changes. The development of the scientific framework will add significant intuition among the researchers for further development of knowledge in the field.

\section{References}

[1] Ballestero, E. and Romero, C. (1998). Multiple Criteria Decision Making and its Applications to Economic Problems, Kluwer Academic Publishers, The Netherlands.

[2] Blaco, A., Delgado, M. and Requena, I. (1995). Improved fuzzy neural networks for solving relational equations, Fuzzy Sets and Systems, 72, pp.311-322.

[3] Bortolan, G. (1998). An architecture of fuzzy neural networks for linguistic processing, Fuzzy Sets and Systems, 100, pp.197-215.

[4] Boussabaine, A.H. (1996). The use of artificial neural networks in construction management: a review, Construction Management and Economics, 14(3), pp.427-436.

[5] Bonabeau, E. (2002). Agent-based modeling: Methods and techniques for simulating human systems, Proceedings of the National Academy of Sciences of the United States of America, May 14, Vol. 99, no. Suppl 3, pp.7280-7287.

[6] Bavelas, A. 1948. A Mathematical Model for Group Structure, Applied Anthropology, Vol.7, pp.16-30.

[7] Carrington, P.J. (2005), Models and Methods in Social Network Analysis, Cambridge University Press, Cambridge.

[8] Clarkson, M.B.E. (1995). A stakeholder framework for analyzing and evaluating corporate social performance, The Academy of Management review, Vol.20, p,92.

[9] Doloi, H. (2012), Application of Behavioural Science and Cognitive Mapping in Project Management Research - Chapter 13, (Eds.) R. Muller, N. Drouin and S. Sankaran, Novel
Research Methods in Project Management, CBS Publishing House, New Delhi, India.

[10]Doloi, H. (2011). Understanding stakeholders' perspective of cost estimation in Project Management, International Journal of Project Management, Vol. 29, pp 622-636.

[11]Doloi, H. (2007) Developing an integrated management system for optimising project options, Journal of Enterprise Information Management, Vol.20(4), pp. 465-486.

[12] Doloi, H, (2012), Assessing stakeholders' influence on social performance of infrastructure projects, Facilities, Vol. 30(11), pp.531-550.

[13] Doloi, H., Haynes, T. and Ma, Z. (2011), Assessing Social Impact in Public Infrastructure Projects using Social Network Analysis, IRNOP $X-$ International Research Network Organising by Project Conference, June 20-22, 2011, Montreal, Canada.

[14]Doloi, H, and Almahmoud, E. (2012), Modelling Social Sustainability in Built Environment, Proceedings of the CIB International Conference of W055, W065, W089, W118, TG76, TG78, TG81 and TG84, 26-29 June 2012, McGill University, Montreal, Canada.

[15] Doloi, H. (2010a). Framework for multi-criteria decision modelling for analysing sustainable management strategy. International Symposium on Coastal Zones and Climate Change: Assessing the Impacts and Developing Adaptation Strategies (CZCC2010), 11 - 13 April 2010, Monash University Gippsland campus, Churchill, Melbourne, Australia.

[16]Doloi, H. (2010b) Balancing stakeholder's requirements in project procurement - have we learnt anything yet?, CIB World Congress 2010, 10-14 May, Salford University.

[17] Doloi, H. (2008a) Life Cycle Project Management - a systems based approach to managing complex projects, VDM Verlag Publisher (June 4, 2008), ISBN-10: 3639015088, ISBN-13: 9783639015089, 384 pages.

[18] Elkington, J. (1998). Partnerships from cannibals with forks: the triple bottom line of 21st-century business, Environmental Quality Management, Vol. 8, pp.37-51.

[19]Fodor, J. and Roubens, M. (1994). Fuzzy Preference Modelling and Multi-criteria Decision Support. Kluwer Academic Publishers, The Netherlands.

[20] Haythornthwaite, C. (1996), Social network analysis: an approach and technique for the study of information exchange, part 1, Library \& Information Science Research, Vol. 18, p. 323.

[21]Festinger, L. 1949. The Analysis of Sociograms Using Matrix Algebra, Human Relations, Vol.2, pp.153-158.

[22] Gunaratnam, D.J. and Gero, J.S. (1994). Effect of representation on the performance of neural networks in structural engineering applications, 
Microcomputers in Civil Engineering, Vol.9, pp.97-108.

[23] Galaskiewcz, J. (1979). The structure of community organisational networks. Social Forces, Vol.57, pp.1346-64.

[24] Granovetter, M. (1973). The strength of weak ties. American Journal of Sociology, Vol.78 No.6, pp.1360-80.

[25] Grimble, R. and Wellard, K. (1997). Stakeholder methodologies in natural resource management - A review of principles, context, experiences and opportunities, Agricultural Systems Journal, Vol.55, No.2, pp.173-93

[26] Haythornthwaite, C. 1996. Social network analysis: An approach and technique for the study of information exchange, part 1. Library \& information science research, Vol.18, p.323.

[27]Hossain, L. (2009). Effect of organisational position and network centrality on project coordination, International Journal of Project Management, Vol.27(7), pp.680-689.

[28] Hossain, L. and Silva, A.d. (2009). Exploring user acceptance of technology using social networks, The Journal of High Technology Management Research,Vol.20(1) pp.1-18.

[29] Jin, X.H. and Doloi, H. (2008). Interpreting risk allocation mechanism in public-private partnership projects: an empirical study in a transaction cost economics perspective, Construction Management and Economics Vol.26, Iss.7, pp.701-721.

[30] Kumar, S.R. and Ghoshal, J. (1998). Neuro-fuzzy reasoning for occluded object recognition. Fuzzy Sets and Systems, 94, pp.1-28.

[31] Kuo, R.J. and Xue, K.C. (1999). Fuzzy neural networks with application to sales forecasting. Fuzzy Sets and Systems, 108, pp.123-143.

[32] Khosla, R. and Dillon, T. (1997). Engineering Intelligent Hybrid Multi-agent Systems, Kluwer Academic Publishers, Boston.

[33] King, W. R. and Cleland, D. I. (1982). Life Cycle Management. Project Management Handbook. Eds. Cleland D. I. and King W.R. Van Nostrand Reinhold Company NY, pp. 209 - 222.

[34] Langston, C. and Ding, G. (2001), Sustainable practices in the built environment (second edition), Butterworth-Heinemann.

[35] Langston, C. (2013) The role of coordinate-based decision-making in the evaluation of sustainable built environments, Construction Management and Economics, Vol.31(1), pp.62-77.

[36] Laufer, A., Denker, G. R. and Shenhar, A. J. (1996). Simultaneous Management: The Key to Excellence in Capital Projects. International Journal of Project Management, 1996, 14(4), pp.198-199.

[37] Lees, B., Branki, C. and Aird, I. (2001), A framework for distributed agent-based engineering design support, Automation in Construction, Vol.10(5), pp.631-637.

[38] Lorterapong, P. and Moselhi, O. (1996). Project- network analysis using fuzzy sets theory. ASCE Journal of Construction Engineering and Management, 122(4), 308-318.

[39]Littig, B. and Griessler, E. (2005). Social sustainability: a catchword between political pragmatism and social theory, International Journal of Sustainable Development, Vol.8, No.1/2, pp.65-79.

[40] Maignan, I. and Ferrell, O. (2004). Corporate social responsibility and marketing: An integrative framework. Journal of the Academy of Marketing Science, 32, pp.13-19.

[41] Majamaa W., Junnila S., Doloi, H. \& Niemistö E. (2008), "End-user oriented Public-Private Partnerships in Real Estate Industries”, International Journal of Strategic Property Management, Vol. 12, pp.1-17.

[42] Morris, P. W. G. and Hough, G . H. (1987). The Anatomy of Major Projects: a Study of the Reality of Project Management. John Wiley and Sons, London.

[43] Mitchell, J.C. (ed.) 1969. Social Networks in Urban Situations, Manchester University Press.

[44] Moreno, J.L. 1953, Who Shall Survive? New York: Beacon House.

[45] Malinowski, B. 1988. Eine wissenschaftliche Theorie der Kultur (A Scientific Theory of Culture), Suhrkamp Verlag, Framnkfurt.

[46] Nwana, H.S and Azarmi, N.(Eds.) (1997). Software Agents and Soft Computing: towards enhancing machine intelligence, Springer-Verlag, Berlin.

[47] Pinto, J.K. (2000). Understanding the role of politics in successful project management, International Journal of Project Management, Vol.18(2), pp.83-152.

[48] Pinto, J. K. and Slevin, D. P. (1988). Critical Success Factors Across the Project Life Cycle. Project Management Journal, Vol. XIX (3), pp.6775.

[49] Pinto, J. K. and Covin, J. G. (1992). Project Marketing: Detailing the Project Manager's Hidden Responsibility. Project Management Journal, Vol. XXII (3), Sept. 1992, pp. 29-34.

[50] Prell, C., Hubacek, K. and Reed, M. (2009). Stakeholder analysis and social network analysis in natural resource management, Society \& Natural Resources, Vol. 22, pp.501-18.

[51] Pryke, S. (2012), Social Network Analysis in Construction, Wiley-Blackwell Publications, Oxford, UK.

[52] Wassernan, S. and Faust, K. 1994. Social network analysis: Methods and applications, Cambridge, New York, NY. 